\title{
APPLICABILITY OF THE FOODTEXTURE PUFF DEVICE FOR RHEOLOGICAL CHARACTERIZATION OF VISCOUS FOOD PRODUCTS
}

\author{
SOFIE MORREN ${ }^{1,5}$, TIM VAN DYCK ${ }^{1}$, FRANK MATHIJS ${ }^{2}$, STIJN LUCA ${ }^{1}$, RUTH CARDINAELS ${ }^{3}$, \\ PAULA MOLDENAERS ${ }^{4}$, BART DE KETELAERE ${ }^{2}$ and JOHAN CLAES ${ }^{1}$
}

${ }^{1}$ Faculty of Engineering Technology, Department of Microbial and Molecular Systems, Leuven Food Science and Nutrition Research Centre (LFoRCe), Lab4Food, KU Leuven, Kleinhoefstraat 4, Geel 2440, Belgium

${ }^{2}$ Department of Biosystems, BIOSYST-MeBioS, Division of Mechatronics, Biostatistics and Sensors, KU Leuven, Leuven, Belgium

${ }^{3}$ Department of Mechanical Engineering Materials Technology, Section Structure and Rheology of Complex Fluids, TU Eindhoven, Eindhoven, The Netherlands

${ }^{4}$ Department of Chemical Engineering Techniques, Division of Soft Matter Rheology and Technology, KU Leuven, Heverlee, Belgium

\section{KEYWORDS}

Foodtexture Puff Device (FPD), fruit puree, molten chocolate, oil, rheology, sugar solution

${ }^{5}$ Corresponding author. TEL:: +32-14-56-23-10; FAX.: +32-14-58-48-59; EMAIL: sofie.morren@kuleuven.be

Received for Publication October 28, 2014 Accepted for Publication March 10, 2015 Published online Article Accepted on March 23, 2015

doi:10.1111/jtxs. 12118

\begin{abstract}
The Foodtexture Puff Device (FPD) is a noncontact rheological measurement device, which applies an air pulse on the sample and measures the subsequent deformation of the sample surface with a laser distance sensor. The deformation behavior is considered as a measure for the rheological properties of the sample. The applicability of this device was studied for use on viscous food products with a broad range of rheological characteristics. In this study, sugar and fat-based systems with a viscosity range of respectively 0.001-6.1 Pa.s and 0.01-5.9 Pa.s were tested. Comparison of the FPD with classical rheological analyses showed that the maximum deformation created by the FPD is strongly correlated to the viscosity. Hence, the FPD is well suited for measurements on sugar-based and fatbased systems. It is capable of providing accurate, noncontact, fast, easy and nondestructive rheological measurements on food products.
\end{abstract}

\section{PRACTICAL APPLICATIONS}

The FPD is a new, noncontact rheological measurement device that can be used for a wide range of food products, including sugar solutions, fruit purees and concentrates, oils and fats, molten chocolate, batter, soft pastry, among others. Furthermore, more solid food products like dough can be measured accurately. The device outputs a displacement signal over time from which information can be extracted. For simple behaviors, this can be performed based on one or a few characteristic values derived from the signal. For more complex foodstuff, the signal as a whole can be used, and techniques such as partial least squares can be used to create a calibration curve that translates the full displacement signal over time into the desired rheological values. Seen the fact that measurement time is short, the FPD is suitable for in-line as well as for R\&D applications and can replace classical devices that are often time consuming and require sample preparation. 


\section{INTRODUCTION}

Rheological measurements can be divided into two main groups, i.e., objective tests (using instrumentation) and sensory tests (based on human perception). Objective tests are performed by means of instruments, sensory tests by persons. Objective tests can be subdivided into fundamental and empirical tests. An overview of the major rheological measurement techniques is given in Fig. 1. In fundamental tests, a well-defined sample geometry is subjected to controlled stress or strain conditions. The test can be carried out with a rheometer or in some cases a texture analyzer or viscometer. A texture analyzer can only perform fundamental measurements when the exact dimensions of the sample are known. Thereby, the strain rate needs to be adapted in function of the deformation of the sample. Experiments with a viscometer are fundamental when using the small sample cup, whereby the cup and spindle have well-defined dimensions. These measurements are generally slow to perform and require expensive equipment. Empirical tests are derived from practical experience. These tests are usually easy to perform, rapid and less expensive. The main disadvantage of this type of measurement for use in the food industry is that mostly there are no ISO standards available. Examples of equipment used for this type of tests are a Bostwick consistometer, a viscometer and a texture analyzer (Bourne 2002). The Foodtexture Puff Device (FPD) is another example of an empirical apparatus.
Existing devices for rheological characterization have several disadvantages. Firstly, the samples often need to be manipulated, which can destroy or alter their microstructure. Secondly, the measurements are usually slow to perform. For the viscometer that can only provide relative viscosity values, the dimensions of the measuring recipient and spindle need to be identical for comparisons of different measurements. Very simple methods such as tests with a Bostwick consistometer are not very precise. Consequently, it is impossible to distinguish between samples with small differences in rheological behavior. Moreover, the Bostwick consistometer is only useful for a small range of products, i.e., products with a low-to-medium viscosity (Bourne 2002).

The FPD, a test that is used in the present investigation, does not have these disadvantages. The FPD is a fast, nondestructive and noncontact device that is easy to use. Furthermore, the sample preparation step is only very limited or even absent. Additionally, the sample can mostly be examined in the original packaging. Hence, it will not be disturbed and its microstructure will remain intact. For the food industry, those characteristics are very appealing and limit the effect of the major advantage of the FPD, which is the combination of a fast and easy, yet objective, measurement. In that way, the production can be monitored closely with human errors. Because the measurement signal is very rich, applications in $\mathrm{R} \& \mathrm{D}$ are also possible when using the partial least squares (PLS)

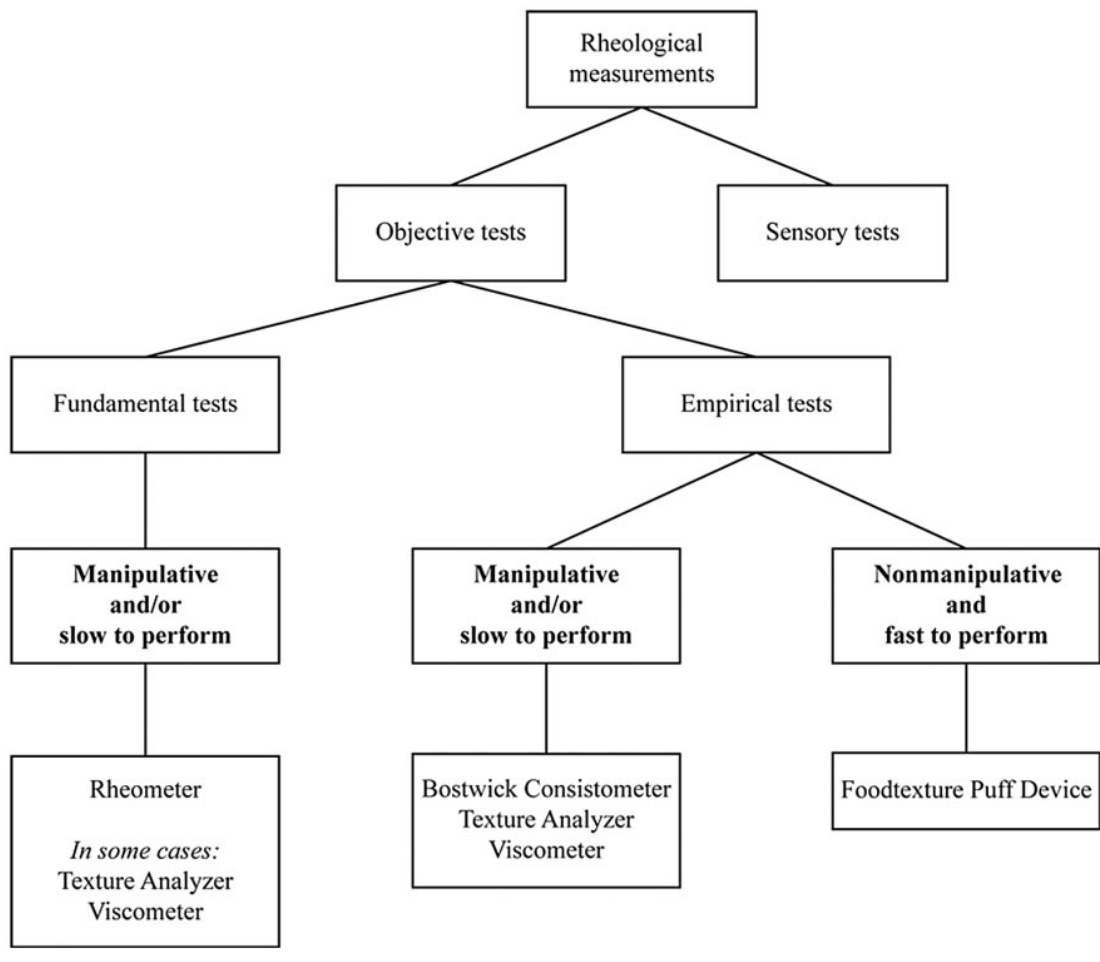

FIG. 1. SCHEMATIC REPRESENTATION OF RHEOLOGICAL MEASUREMENTS (FROM BOURNE 2002) 
technique that extracts the relevant information from the full signal.

The working principle of the FPD is based on the generation of a controlled air pulse toward the sample surface and measuring the resulting deformation of the sample surface with a laser distance sensor. The resulting deformation is considered as a measure for the rheology of the sample. This principle was first introduced by Prussia et al. (1994). Their patent described a design for measuring the firmness of fruit in an efficient, noncontact and nondestructive way. Furthermore, the authors spent much effort on improving the robustness of the method for products with a rough and uneven surface. In their research, the Magnus-Taylor puncture test was used as a reference measurement to determine the firmness of the fruit. Hung et al. (1999) investigated the applicability of the device for measuring the firmness of peaches and reported high correlations with the penetrometer firmness and peach mass. A similar device was developed by McGlone et al. (1999). McGlone and Jordan (2000) investigated the applicability of this device for use on kiwifruit and apricots and concluded that the device was only suitable for coarse screening of fruit. Lee et al. (2008) studied this method for use on raw poultry meat to predict the tenderness of the cooked poultry meat. As a reference, the tenderness of the cooked poultry meat was measured instrumentally with the Meullenet-Owens and Blunt-Meullenet-Owens razor shear, and with sensory analysis. The deformation resulting from the air pulse is a good measure for the tenderness of the cooked poultry meat.

Based on the idea of Prussia et al. (1994), Bamelis and De Baerdemaeker (2006) developed the FPD to monitor the coagulation of milk during cheese making. The FPD differed from the idea of Prussia et al. because that device was only suitable for use on solid products like fruit and poultry meat. Thus, it was never tested before on liquid products. Bamelis and De Baerdemaeker found a clear correlation between the deformation measured by the FPD and the firmness (i.e., storage modulus) of the cheese curd at different stages of the coagulation. Moreover, the device seemed to be appropriate for fast laboratory measurements and in-line applications.

In the present study, the use of the FPD for rheological measurements on sugar solutions, glucose syrups, fruit purees and concentrates, oils and fats, and chocolate will be assessed. Rotational measurements with a classical rheometer were carried out as a reference. The fundamental rheological measurement protocols were chosen based on typical characterization methods for the different food samples, as described in literature. In the present article, the focus is on viscosity as a reference measure. For dough systems, also viscoelastic properties were related to the FPD signal. This is, however, beyond the scope of the present article.

\section{MATERIALS AND METHODS}

\section{Preparation of Samples}

Sugar Solutions. Seven sugar solutions were prepared with sucrose and water. Different amounts of sucrose were added to boiling water and afterwards the solutions were cooled down to the measurement temperature. A wide range of sucrose concentrations was prepared, ranging from 10 to $70^{\circ} \mathrm{Brix}$ (steps of $10^{\circ} \mathrm{Brix}$ ). The sucrose concentration of the solutions was determined using a refractometer (Refractometer HI 96801, Hanna Instruments, Woonsocket, Rode Island) and approximated the desired value up to $+/-$ $0.4^{\circ}$ Brix. Five percent of low-fat milk was added to make the solutions opalescent, a desired property when using laser displacement sensors as used in the FPD (see further). The milk caused a minor change in the viscosity of the sugar solutions (maximum 5\%, data not shown). But because it was added in the same amount to all samples, i.e., samples measured with the FPD and the rheometer, correlations could be made. Measurements performed with both the FPD and the rheometer were set at 7,20 and $40^{\circ} \mathrm{C}$, resulting in a total of 21 samples.

Glucose Syrups. Thirteen glucose syrups with dextrose equivalent values ranging from 27 to 97 were obtained from Cargill (Minneapolis, Minnesota, United States) and Tereos Syral (Marckolsheim, France). Samples were used as received and brought to the measurement temperature of $50^{\circ} \mathrm{C}$ for both measurements with the FPD and the rheometer.

Fruit Purees and Concentrates. Eleven ready-made fruit purees and concentrates (FrieslandCampina, Amersfoort, The Netherlands) with diverse types of fruit (peach, pear, strawberry, cranberry, etc.) were also examined. Measurements performed with both the FPD and the rheometer were executed at 7,20 and $40^{\circ} \mathrm{C}$.

Oils and Fats. Twelve samples of oils and fats (sunflower oil, olive oil, refined soy oil, hydrogenated soy oil, refined palm oil, hydrogenated palm oil, refined rapeseed oil, hydrogenated rapeseed oil with three degrees of hydrogenation, i.e., 15, 23 and 36, and two types of free fatty acids) with a wide variety of fatty acids were investigated (Cargill, Minneapolis, Minnesota, United States; FrieslandCampina, Amersfoort, The Netherlands; Vandemoortele, Gent, Belgium). The oils and fats were molten in a water bath before analysis. Up to $0.2 \mathrm{wt} \%$ titanium oxide was added to all the samples measured with the FPD and the rheometer, making the oils and fats opalescent and the samples surface detectable for the laser distance sensor of the FPD. This had no influence on the rheological properties of the oils and fats. The measurement temperatures of the oils and fats for 
both the FPD and the rheometer measurements were 25, 40, 55 and $70^{\circ} \mathrm{C}$. The fat samples were not measured at $25^{\circ} \mathrm{C}$ because of the higher melting point.

Chocolate Samples. Finally, nine chocolates (several types of fondant, milk and white chocolate) (Puratos Belcolade, Erembodegem, Belgium; Cargill, Minneapolis, Minnesota, United States) with different composition, and thus viscosity values, were molten in a water bath with a controlled temperature of $50^{\circ} \mathrm{C}$. Standardization was obtained by stirring the chocolate after it was molten, followed by $20 \mathrm{~min}$ of rest in the water bath at $42^{\circ} \mathrm{C}$. Measurements performed with both the FPD and the rheometer were executed at $40^{\circ} \mathrm{C}$.

All measurement temperatures were achieved by placing the samples in a beaker which was placed in a water bath with controlled temperature, except for the measurements at $7^{\circ} \mathrm{C}$. Tests at $7^{\circ} \mathrm{C}$ were carried out on samples directly taken from the refrigerator at $7^{\circ} \mathrm{C}$. Tests were started when temperature equilibrium was reached. No further temperature control was required during the experiments with the FPD because it is a fast measurement method (maximum duration of a measurement is $5 \mathrm{~s}$ ).

\section{Measurements with the FPD}

The FPD applies a controlled air puff to the surface of the sample and the resulting deformation as function of time is measured by a laser distance sensor (Fig. 2).

Several input parameters of the FPD can be set, such as air pressure and distance of the measuring head to the surface of the sample. For each sample, values for these parameters were chosen with the aim of obtaining a high

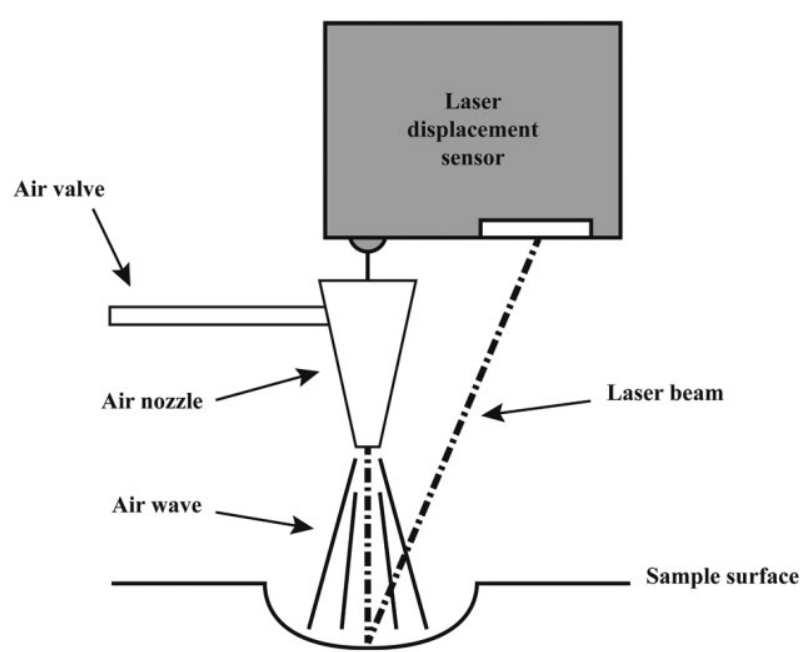

FIG. 2. WORKING PRINCIPLE OF THE FPD (BAMELIS AND DE BAERDEMAEKER 2006) reproducibility. In addition, the duration of the air pulse and measurement time can be chosen. The duration of the air pulse was set at $100 \mathrm{~ms}$ for the sugar-based systems and at $75 \mathrm{~ms}$ for the fat-based systems. It was found that a shorter pulse duration gave more consistent results for those fat-based systems (data not shown).

The deformation as function of time is determined by the rheological characteristics of the product as is illustrated in Fig. 3. Products with low viscosity values displayed an under-damped oscillatory profile (Fig. 3a) whereas products with a higher viscosity or flow stress showed an overdamped profile (Fig. 3b). The observed signal is rich in information and can be described using several characteristic values such as the maximum deformation, the overshoot and the rest value. The maximum deformation is the minimum value obtained whereas the overshoot is the maximum value obtained. The rest value is the value reached at the end of the measurement. Based on our investigation, the maximum deformation is for most food products that display a rather simple behavior the most informative parameter. For this reason, the maximum deformation was mostly used to compare with the viscosity, obtained from the reference method.

The dimensions of the measuring recipients are given in Table 1. For all the samples, except for the molten chocolate, the same beaker was used. For products with a low viscosity, the beaker size influences the measurement profile due

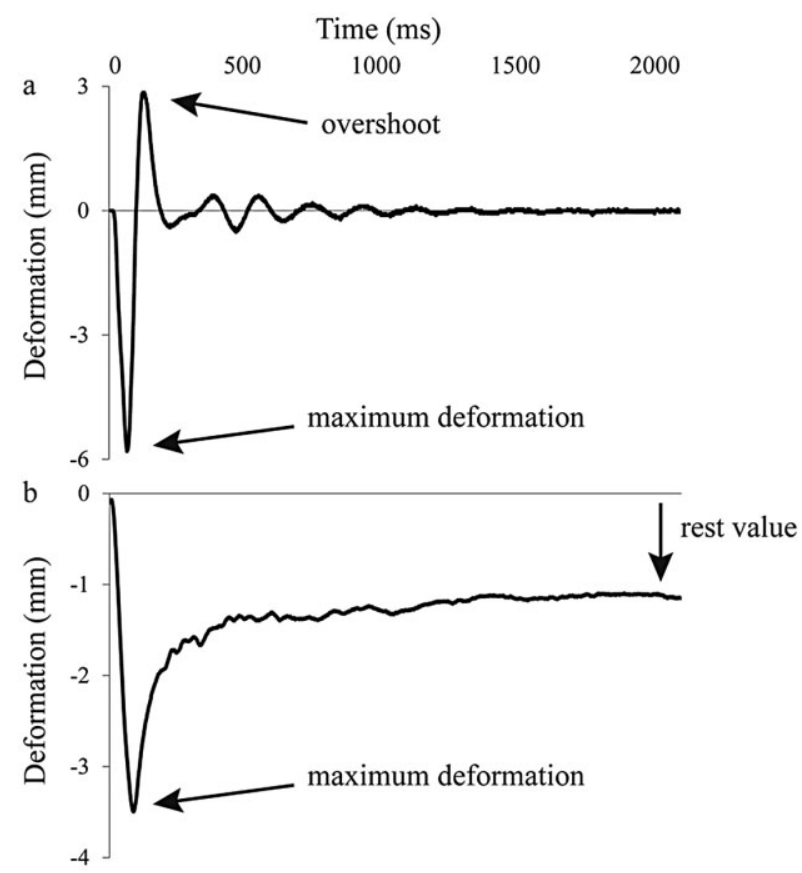

FIG. 3. TWO TYPICAL FPD PROFILES OF LOW VISCOSITY FLUIDS (RAPESEED OIL AT $25^{\circ} \mathrm{C}$ ) (A) AND HIGH VISCOSITY FLUIDS (MOLTEN CHOCOLATE AT $\left.40^{\circ} \mathrm{C}\right)(\mathrm{B})$ 
TABLE 1. DIMENSIONS OF THE MEASURING RECIPIENTS

\begin{tabular}{lllllr}
\hline & Sugar solutions & Glucose syrups & Fruit purees/concentrates & Oils and fats & Molten chocolate \\
\hline Diameter $(\mathrm{mm})$ & 65 & 65 & 65 & 65 & 150 \\
Height $(\mathrm{mm})$ & 75 & 75 & 75 & 75 & 70 \\
\hline
\end{tabular}

to the reflection wave of the liquid against the recipient wall. However, for a diameter of $65 \mathrm{~mm}$, this wave does not influence the maximum deformation or the overshoot (data not shown). Molten chocolate was examined using a beaker with a larger diameter to perform multiple measurements at different locations.

Firstly, sugar-based systems (sugar solutions, glucose syrups, fruit puree and concentrates) were measured with the FPD. To make sure all the sugars are in solution, all samples were stirred before starting the measurement as well as before each repetition. Sugar solutions have very low viscosity values (less than $0.1 \mathrm{~Pa}$.s), requiring low air pressure values. A beaker with the sugar solution was placed under the measuring head of the FPD. All the sugar solutions were measured at a distance of $35 \mathrm{~mm}$ and using an air pressure of 200 mbar. As an additional experiment, the air pressure of the sugar solutions with 10 and $50^{\circ}$ Brix was also varied from 50 to 500 mbar to investigate the linearity of the deformation with respect to the air pressure. Ten repetitions for each concentration were performed. Glucose syrups have higher viscosities and thus require a higher air pressure. Glucose syrups were measured in a range of 5001,500 mbar at $35 \mathrm{~mm}$ distance. Five repetitions were performed. Fruit purees and concentrates were measured at a distance of $35 \mathrm{~mm}$, with an air pressure of respectively 250,750 and 2,000 mbar, depending on the viscosity of the sample. Certain fruit purees and concentrates were measured in an air pressure range. Three repetitions were carried out each on a new sample (Table 2).

Secondly, fat-based systems (oils and fats, and molten chocolate) were measured using the FPD. Oils and fats were measured at 50 and $200 \mathrm{mbar}$ at a distance of $45 \mathrm{~mm}$. Ten repetitions were performed on each oil sample. For molten chocolate, the specific beaker was placed under the measuring head of the FPD. Then six repetitions on equidistant places at the sample surface were carried out using a constant air pressure. After this measurement, the molten chocolate was stirred in the beaker and put in the water bath at $42^{\circ} \mathrm{C}$ for $20 \mathrm{~min}$ to rest. This resting period was important because of the thixotropic behavior of molten chocolate. After $20 \mathrm{~min}$, again six repetitions were performed, but this time using another air pressure. With this procedure, the air pressure for molten chocolate ranged from 100 to 2,500 mbar with steps of $100 \mathrm{mbar}$ (distance from the head to the surface was $25 \mathrm{~mm}$ ) (Table 2).

\section{Fundamental Rheological Measurements}

Fundamental rheological measurements were carried out with a rheometer with a Peltier system to control the temperature (Physica MCR 301, Anton Paar Benelux BVBA, Gentbrugge, Belgium). Rotational measurements were performed on all samples to determine the viscosity. For every product, three repetitions were performed using a new sample for each repetition.

The viscosities of sugar solutions were determined in a shear rate ramp with a concentric cylinder system with a ratio of inner to outer radius of 0.96 . The shear rate was varied from 0.1 to $100 \mathrm{~s}^{-1}$ over $155 \mathrm{~s}$ (Yoğurtçu and Kamişh 2006). The slope of the curve (shear stress in function of shear rate) was taken as the viscosity. This was possible due to the Newtonian behavior of sugar solutions. Glucose syrups were tested with a plate-plate system of $25 \mathrm{~mm}$ diameter and a gap of $1 \mathrm{~mm}$. A constant shear rate of $10 \mathrm{~s}^{-1}$ for $120 \mathrm{~s}$ was applied and the mean viscosity value was taken. Fruit purees and concentrates were tested with a plate-plate system of $50 \mathrm{~mm}$ diameter and a gap of $2 \mathrm{~mm}$. These products showed shear-thinning behavior. However, to obtain a single viscosity value as a reference, these samples were analyzed at a constant shear rate of $10 \mathrm{~s}^{-1}$ during $250 \mathrm{~s}$, and every $5 \mathrm{~s}$ a measuring point was registered. The mean viscosity value was calculated.

Oils and fats were measured with a plate-plate system of $50 \mathrm{~mm}$ diameter and a gap of $1 \mathrm{~mm}$. A shear rate ramp

TABLE 2. PARAMETERS OF THE FPD MEASUREMENTS

\begin{tabular}{|c|c|c|c|c|c|}
\hline FPD parameters & Sugar solutions & Glucose syrups & Fruit puree/concentrates & Oils and fats & Molten chocolate \\
\hline Air pressure (mbar) & $200 *$ & $500-1,500$ & $250 / 750 / 2,000$ & $50 / 200$ & $100-2,500$ \\
\hline Distance (mm) & 35 & 35 & 35 & 45 & 25 \\
\hline Duration of air pulse (ms) & 100 & 100 & 100 & 75 & 75 \\
\hline Measurement time (ms) & 2,500 & 2,500 & 2,500 & 2,500 & 2,500 \\
\hline Repetitions & 10 & 5 & 3 & 10 & 6 \\
\hline
\end{tabular}

* For the sugar solutions with 10 and $50^{\circ}$ Brix, an air pressure range from 50 to 500 mbar was also performed. 
from 10 to $1,000 \mathrm{~s}^{-1}$ over $29 \mathrm{~s}$ was applied and the slope of the curve obtained, shear stress in function of shear rate, was taken as viscosity value (Kim et al. 2010). The viscosity values of the molten chocolate samples were determined with a concentric cylinder system following the standard procedure of the International Cocoa Organization. Because of the thixotropic behavior of chocolate, reproducibility of the sample preparation has to be guaranteed. After resting for $20 \mathrm{~min}$ in the water bath, the sample was filled in the cup of the concentric cylinder and subsequently a pre-shear of $5 \mathrm{~s}^{-1}$ for $15 \mathrm{~min}$ was performed. For the actual test, a shear rate ramp from 5 to $50 \mathrm{~s}^{-1}$ (ramp up) over $120 \mathrm{~s}$ was applied and thereafter the shear rate was decreased from 50 to $5 \mathrm{~s}^{-1}$ (ramp down) in $120 \mathrm{~s}$. The shear stress at a shear rate of $30 \mathrm{~s}^{-1}$ (ramp up) represented the viscosity (Afoakwa et al. 2009).

\section{Statistical Analyses}

Statistical analyses were performed with IBM SPSS Statistics 19.0 (Armonk, NY). To demonstrate potential significant differences, analysis of variance (ANOVA) was carried out. After a positive omnibus F-test, post hoc multiple comparisons (Duncan) were carried out. To examine whether regression lines were significantly dissimilar, an analysis of covariance (ANCOVA) model was fitted. A significance level of $5 \%$ was applied throughout all analyses.

\section{RESULTS AND DISCUSSION}

Fluid-like sugar-based and fat-based systems with a wide variety of viscosities were tested in this study. This variety is illustrated with the viscosity range of the different products, as obtained with the fundamental rheological measurements (Table 3).

\section{Sugar-Based Systems}

The results of the fundamental measurements of the sugar solutions indicate the Newtonian behavior. Glucose syrups, fruit purees and concentrates have a shear-thinning behav-

TABLE 3. OVERVIEW OF THE RHEOLOGICAL RESULTS (THE GIVEN VISCOSITIES ARE THE MINIMUM AND MAXIMUM VALUES MEASURED FOR THE DIFFERENT SAMPLES)

\begin{tabular}{ll}
\hline & Viscosity (Pa.s) \\
\hline Sugar solutions & $0.001-0.1$ \\
Glucose syrups & $0.75-14.4$ \\
Fruit purees and concentrates & $0.02-6.1$ \\
Oils and fats & $0.01-0.1$ \\
Molten chocolate & $0.37-5.9$ \\
\hline
\end{tabular}

ior and fruit purees and concentrates sometimes show a thixotropic behavior as well (data not shown).

When measuring with the FPD, the sugar solutions show an under-damped oscillatory profile (similar to Fig. 3a) because of the very low viscosity values. On the other hand, fruit purees and concentrates show an over-damped profile (similar to Fig. 3b). Sometimes a rest value was detectable probably due to the higher viscosity. A reasonable explanation for this observation is the small time frame measured, i.e., only $2 \mathrm{~s}$, which is too short for a full recovery of the product surface to its starting position.

Furthermore, surface tension will have an influence on the results obtained with the FPD. However, for the systems under study (sugar solutions, glucose syrups or fruit purees and concentrates), the differences in surface tension were small as compared to the forces and deformations applied by the air pulse (data not shown).

The results of the experiments with the FPD on two sugar solutions and a fruit puree are demonstrated in Fig. 4. The maximum deformation is shown as a function of

$$
\mathrm{a}
$$
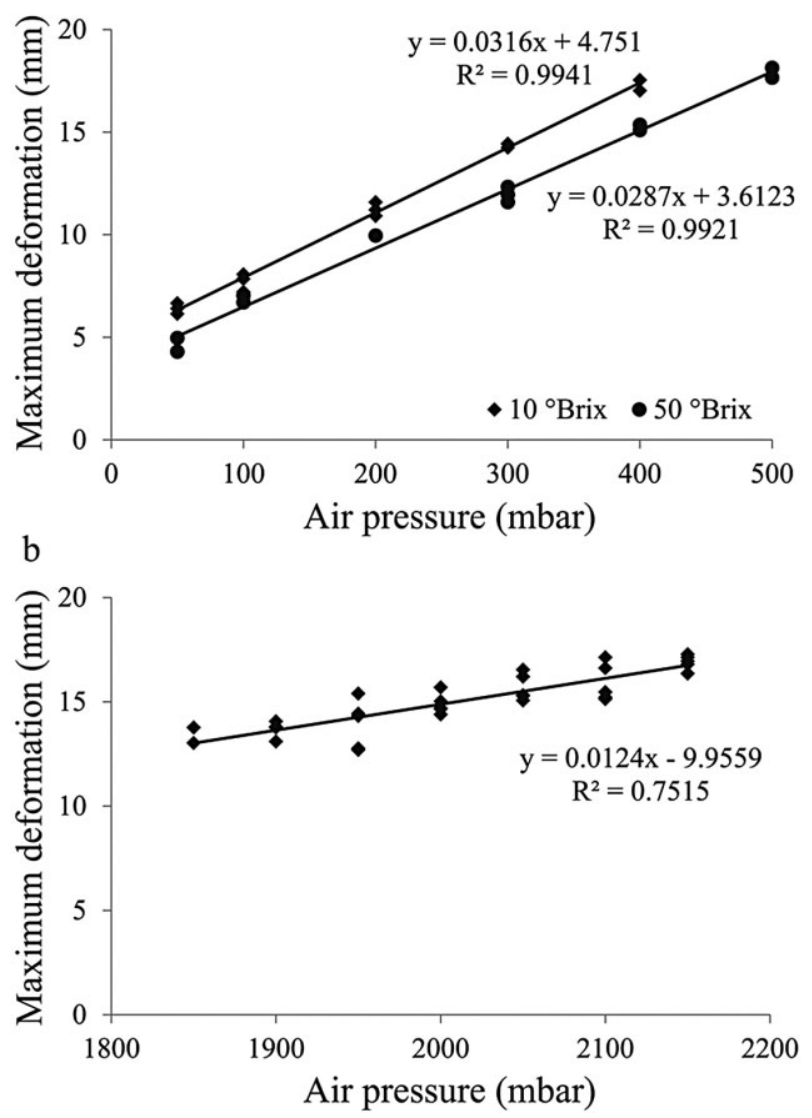

FIG. 4. MAXIMUM DEFORMATION OF TWO SUGAR SOLUTIONS ( 10 AND $50^{\circ}$ BRIX) AT $20^{\circ} \mathrm{C}$ (A) AND A FRUIT PUREE (PEACH/PEAR) AT $7^{\circ} \mathrm{C}$ (B) AS A FUNCTION OF AIR PRESSURE 
the air pressure. A strong linear correlation between the maximum deformation and the air pressure was found, which indicates that the FPD delivered consistent results. The correlation coefficient of the fruit puree is lower as compared to that of the sugar solutions, which is probably due to the heterogeneity of the product. Similar results were obtained for the glucose syrups. Figure 4 illustrates that the FPD is able to establish a linear pressure-deformation relation as an equivalent of a classical stress-deformation curve. Furthermore, measurements with the FPD gave rather small standard deviations on the maximum deformation (a coefficient of variation of about 5\%), which makes it a reproducible method. The slope and intercept of the regression line for the maximum deformation of the sugar solution of $10^{\circ}$ Brix differed significantly from the one of the solution with $50^{\circ}$ Brix. Moreover, the values of the maximum deformation of the $10^{\circ}$ Brix sugar solution were higher than the values of the $50^{\circ}$ Brix solution for each air pressure.

Figure 5 demonstrates the effect of the sugar concentration on the viscosity and corresponding deformation in the
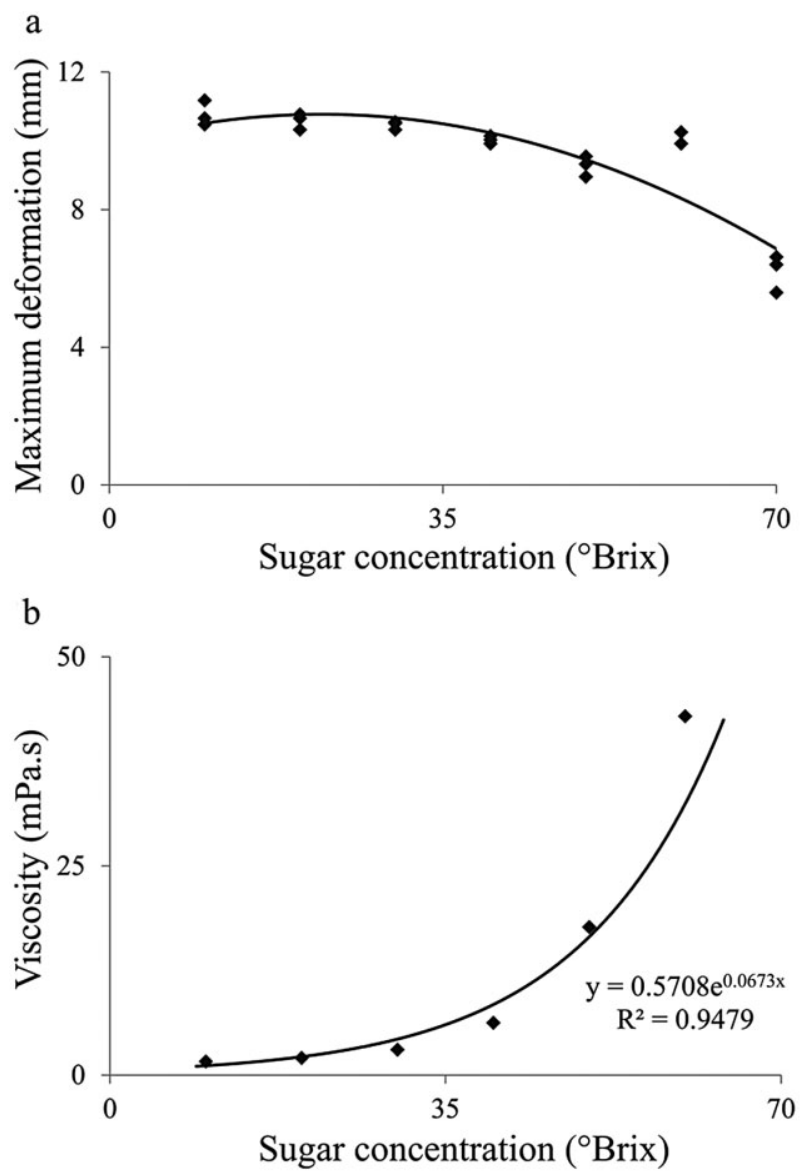

FIG. 5. MAXIMUM DEFORMATION (A) AND VISCOSITY (B) AT $20^{\circ} \mathrm{C}$ AS A FUNCTION OF SUGAR CONCENTRATION
FPD measurements for a range of sugar solutions. Figure 5a gives an overview of the maximum deformation values of all sugar solutions at 200 mbar. Figure $5 \mathrm{~b}$ shows the viscosity values of all the sugar solutions tested. Whereas the viscosity increases with increasing sugar concentration, the maximum deformation decreases with increasing sugar concentration. Despite the deviating result of the sugar solution with $60^{\circ}$ Brix, it can be seen from Fig. 5 that the FPD qualitatively captures the effect of sugar concentration on the flow behavior of sugar solutions. The dependency of the viscosity on the sugar concentration was less pronounced at low sugar concentrations and increased with sugar concentration, clearly reflecting the nonlinear dependency of viscosity, and of maximum deformation, as a function of sugar concentration. The curvilinear relation between the sugar concentration and the viscosity was also found by Soesanto and Williams (1981) and Quintas et al. (2006).

The temperature dependency of the maximum deformation of several sugar solutions and fruit concentrates is demonstrated respectively in Fig. 6a,b. The measurements
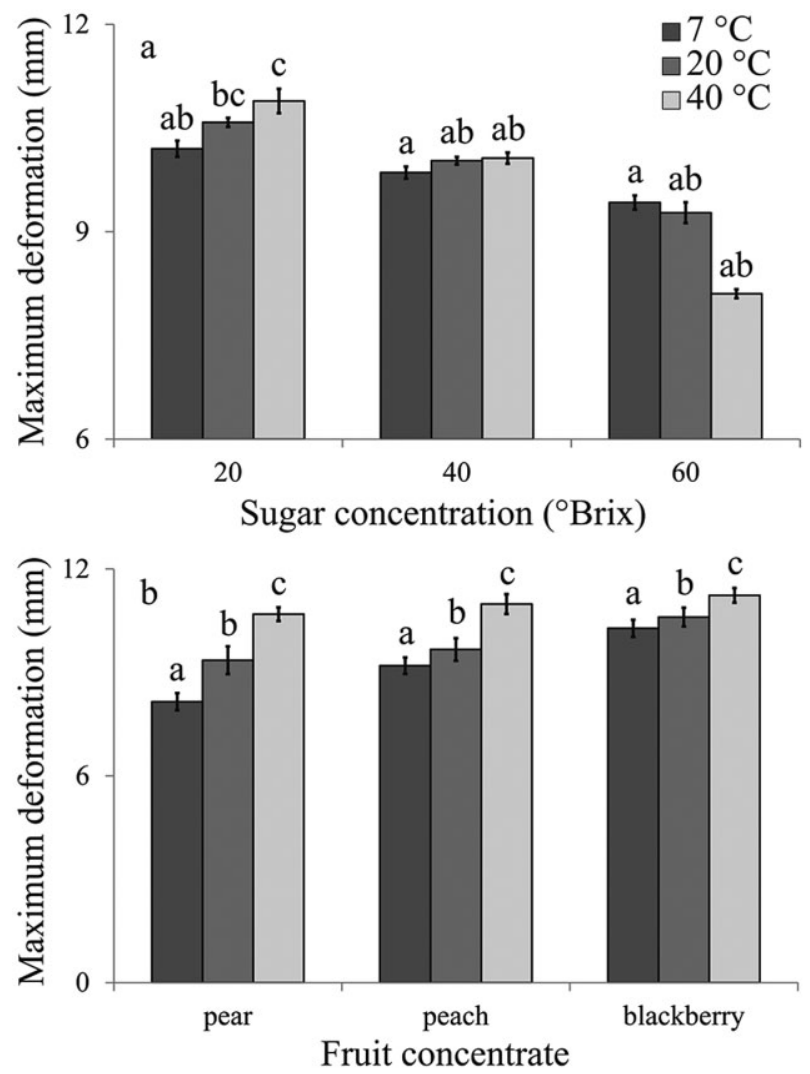

FIG. 6. TEMPERATURE DEPENDENCY OF SUGAR SOLUTIONS (A) AND FRUIT CONCENTRATES (B). DIFFERENT LETTERS ABOVE THE BARS INDICATE SIGNIFICANT DIFFERENCES WITH A SIGNIFICANCE LEVEL OF $5 \%$ 
TABLE 4. VISCOSITY VALUES (PA.S) OF THREE FRUIT CONCENTRATES AT DIFFERENT TEMPERATURES

\begin{tabular}{llrrr}
\hline & & \multicolumn{1}{c}{$7^{\circ} \mathrm{C}$} & \multicolumn{1}{c}{$20^{\circ} \mathrm{C}$} & \multicolumn{1}{c}{$40^{\circ} \mathrm{C}$} \\
\hline Sugar solutions & $20^{\circ}$ Brix & 3.020 & 2.051 & 1.303 \\
& $40^{\circ} \mathrm{Brix}$ & 10.378 & 6.251 & 3.398 \\
& $60^{\circ} \mathrm{Brix}$ & 94.106 & 42.889 & 16.844 \\
Fruit concentrates & Pear & 1.070 & 0.351 & 0.052 \\
& Peach & 0.405 & 0.143 & 0.031 \\
& Blackberry & 0.174 & 0.077 & 0.021 \\
\hline
\end{tabular}

shown were carried out at 200 mbar for the sugar solutions and at 250 mbar for the fruit concentrates. The maximum deformation increased with increasing temperature. Although the FPD was not able to make a significant distinction for the sugar solutions at each temperature, there was an apparent trend. However, for the sample with $60^{\circ}$ Brix, the maximum deformation was inversely proportional to the temperature. No suitable explanation for this phenomenon could be found. For the fruit concentrates, all three types were significant different in maximum deformation for the three temperatures. Similar results were obtained with the rheometer (Table 4).

The correlation between the maximum deformation (FPD) and the viscosity (rheometer) at all measurement temperatures for sugar solutions and fruit purees and concentrates is depicted respectively in Fig. 7a,b. The correlation between the maximum deformation and viscosity values showed a strong linear relation $\left(R^{2}>0.9\right)$. Because of this linear relation found for the sugar solutions, it can be stated that the FPD was able to describe the Newtonian behavior that is typical for sugar solutions (Recondo et al. 2006; Quintas et al. 2006). For the fruit purees and concentrates, a curvilinear relation was found. However, two groups can be distinguished. In the first group at the low viscosity values, measurements were performed on fruit concentrates, whereas in the second group at the higher viscosity values, measurements were performed on fruit purees. It seems that the FPD showed a stronger capability in distinguishing the fruit concentrates than the fruit purees. Because of the good correlations between the maximum deformation and the viscosity, the FPD may replace the classical rheometer when empirical results contain sufficient information. In addition, the results from Fig. 7 can be used as calibration curves which allows to calculate the viscosity from the maximum deformation.

\section{Fat-Based Systems}

The results of the fundamental measurements confirmed the expected Newtonian behavior of the oils and fats. Molten chocolate demonstrated a shear-thinning and thixotropic behavior, and also a yield stress was detected.

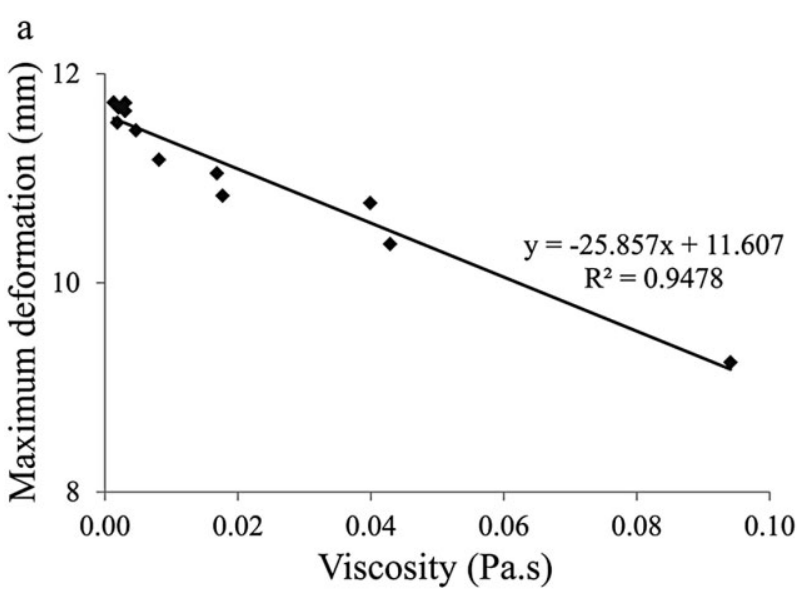

b

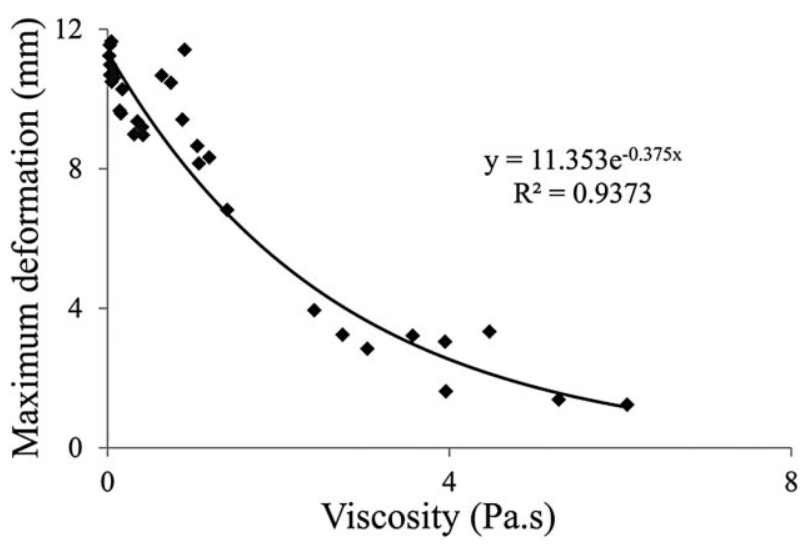

FIG. 7. CORRELATION BETWEEN FPD AND RHEOMETER OF SUGAR SOLUTIONS (A) AND FRUIT PUREES AND CONCENTRATES (B)

As with the sugar-based systems, products with low viscosity values such as oils and fats showed an under-damped oscillatory profile, whereas products with a higher viscosity such as molten chocolate showed an over-damped profile with a rest value (Fig. 3).

The maximum deformation for a white molten chocolate as a function of the air pressure is shown in Fig. 8. A strong linear relation $\left(R^{2}>0.99\right)$ of the maximum deformation and the air pressure was observed, which demonstrates the consistent results of the FPD.

Figure 9 presents a comparison of all types of chocolate at $40^{\circ} \mathrm{C}$. Figure $9 \mathrm{a}$ shows the results of the FPD measured at 1,000 mbar. The viscosity values at $30 \mathrm{~s}^{-1}$ are displayed in Fig. 9b, which illustrates the wide variety of chocolate samples that were tested. When performing the post hoc Duncan test using a significance level of $5 \%$ for the maximum deformation, all samples were significantly different. On the contrary, the rheometer could only distinguish four groups at the same significance level. As for the sugar-based systems, also the fat-based systems showed a relative small standard deviation in maximum deformation 


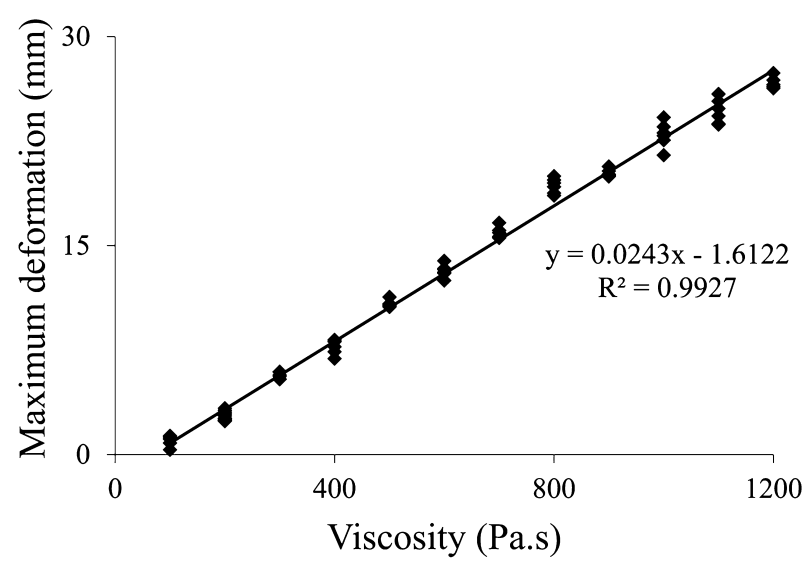

FIG. 8. EXAMPLE OF A WHITE MOLTEN CHOCOLATE $\left(40^{\circ} \mathrm{C}\right)$, ANALYZED WITH SEVERAL AIR PRESSURES

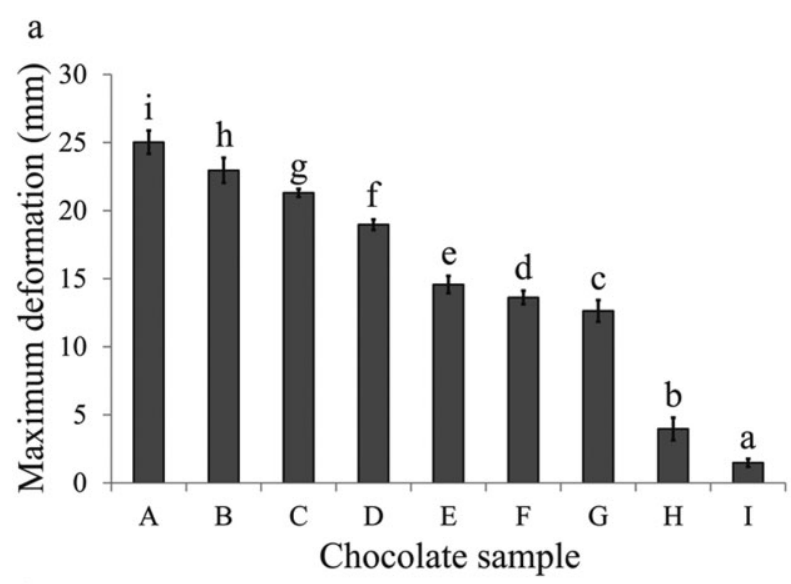

b

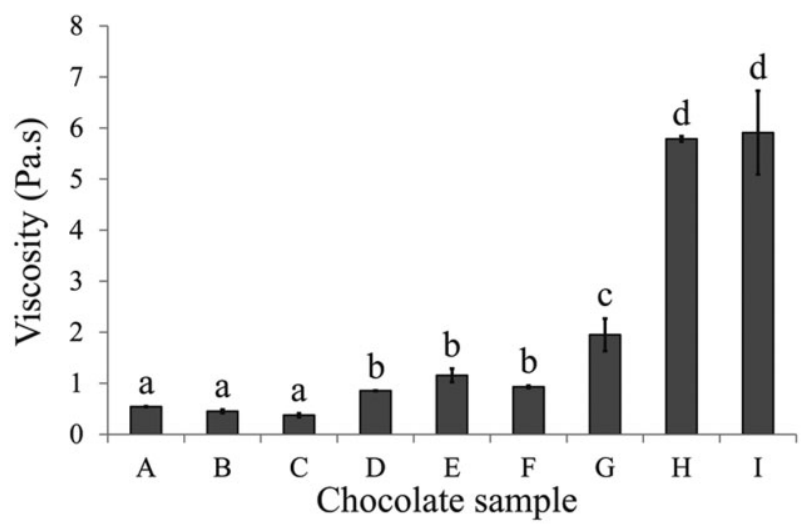

FIG. 9. MAXIMUM DEFORMATION VALUES (A) AND VISCOSITY VALUES (B) OF ALL CHOCOLATE SAMPLES AT $40^{\circ} \mathrm{C}$. DIFFERENT LETTERS ABOVE THE BARS INDICATE SIGNIFICANT DIFFERENCES WITH A SIGNIFICANCE LEVEL OF 5\%

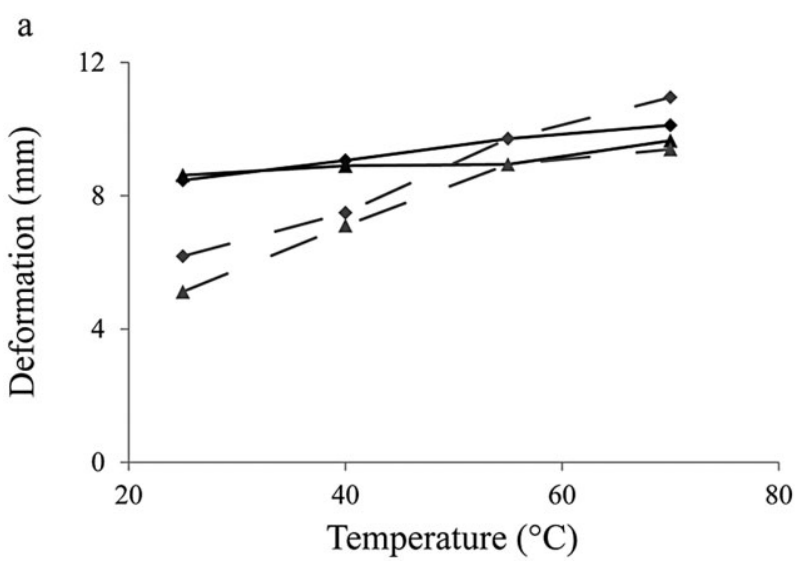

b

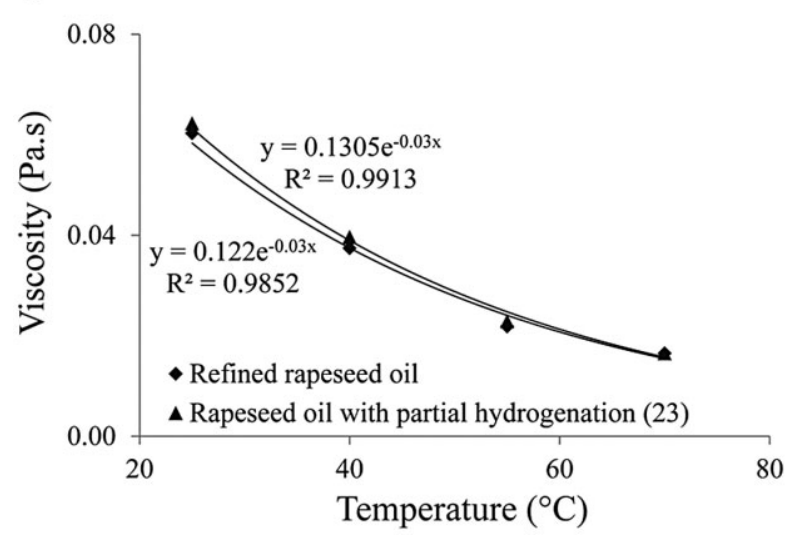

FIG. 10. MAXIMUM DEFORMATION (BLACK) AND OVERSHOOT (GRAY) (A) AND VISCOSITY (B) AS FUNCTION OF TEMPERATURE

or overshoot (a coefficient of variation of approximately $6 \%$ ), and therefore measurements with the FPD could be considered as being reproducible.

Figure 10 shows the temperature dependency of a refined and hydrogenated oil sample as measured using the maximum deformation and the overshoot values from the FPD (Fig. 10a), as well as in terms of the viscosity (Fig. 10b). The maximum deformation increased marginally with temperature whereas the increase for the overshoot was more pronounced. This indicated that the overshoot is better able to distinguish very small differences in viscosity when measuring low viscosity fluids.

The viscosity of all oil samples changed exponentially as a function of temperature $\left(R^{2}>0.9\right)$. This temperature dependency of the viscosity is described by the Arrhenius equation (Kim et al. 2010):

$$
\eta=A \cdot \exp \left(\frac{E_{\mathrm{a}}}{R \cdot T}\right)
$$

where $\eta$ is viscosity (Pa.s); $E_{\mathrm{a}}$ is activation energy $(\mathrm{J}) ; T$ is temperature (K); and $A$ and $R$ are constants. 


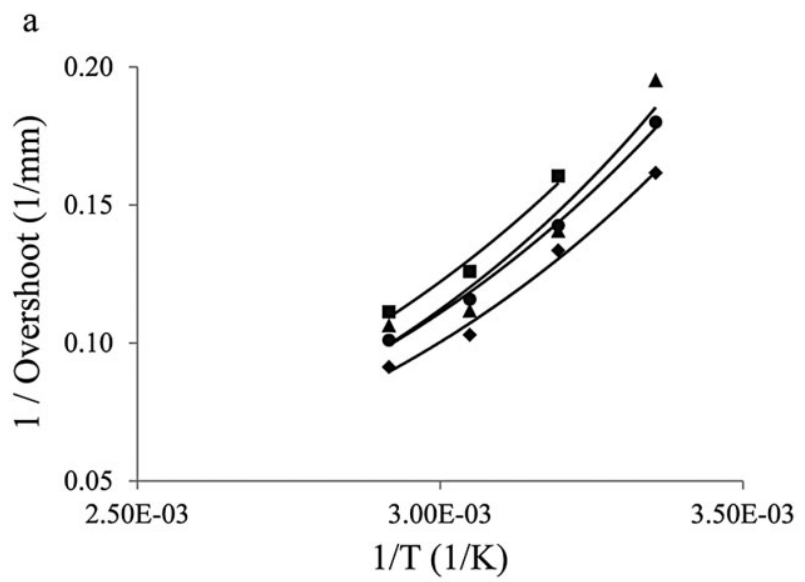

$\mathrm{b}$

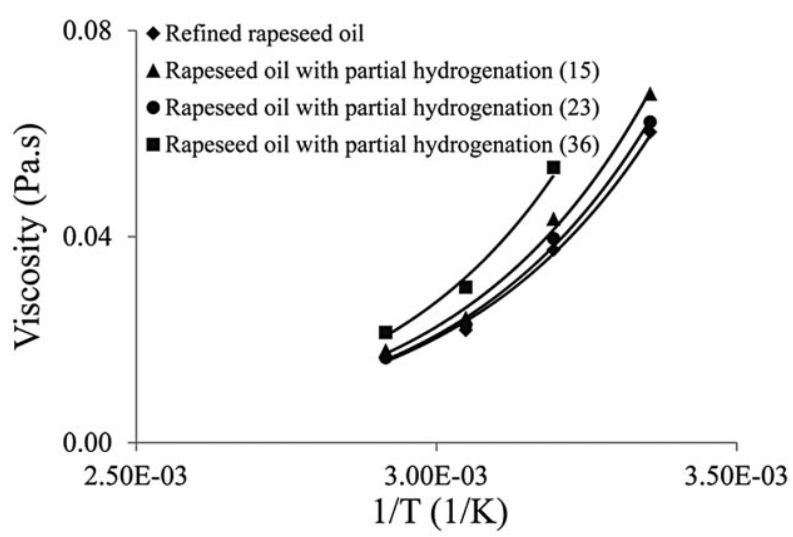

FIG. 11. 1/OVERSHOOT (A) AND VISCOSITY (B) AS FUNCTION OF $1 / T$ FOR RAPESEED OIL AT SEVERAL DEGREES OF HYDROGENATION

Similarly, the temperature dependency of the overshoot was modeled using an Arrhenius equation:

$$
\frac{1}{\text { overshoot }}=a \cdot \exp \left(\frac{E_{F P D}}{R \cdot T}\right)
$$

where $E_{\mathrm{FPD}}$ is calculated activation energy for the FPD; $T$ is temperature $(\mathrm{K})$; and $a$ and $R$ are constants.

The results of the rapeseed oils are depicted in Fig. 11. The other oils and fats showed analogous profiles. The profiles for all types of oils and fats obtained with the FPD were similar to the profiles generated with the rheometer data. The FPD was thus capable to describe the temperaturedependent behavior of oils and fats.

The activation energy of all the measurements with the $\mathrm{FPD}\left(E_{\mathrm{FPD}}\right.$ from Eq. 2$)$ and the rheometer ( $E_{\mathrm{a}}$ from Eq. 1$)$ is presented in Fig. 12. At the lower $E_{\text {a }}$ values, a correlation seems to exist, but this was not the case at higher activation energies. It requires further research to use the FPD measurements as a measure for activation energies.

In Fig. 13, the correlation between the FPD data (the overshoot and the maximum deformation respectively) and

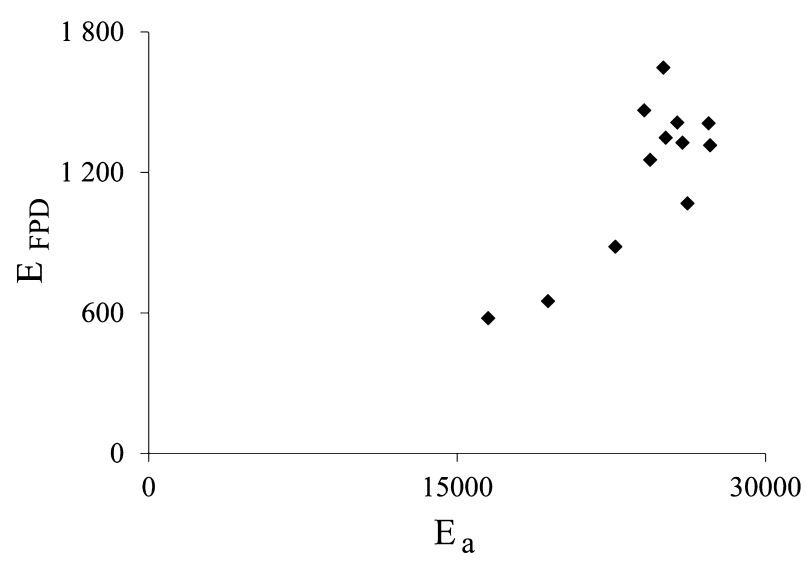

FIG. 12. CORRELATION OF THE CALCULATED ACTIVATION ENERGY FROM THE RHEOMETER DATA ( $\left.E_{\mathrm{A}}\right)$ AND THE FPD DATA (EFPD)

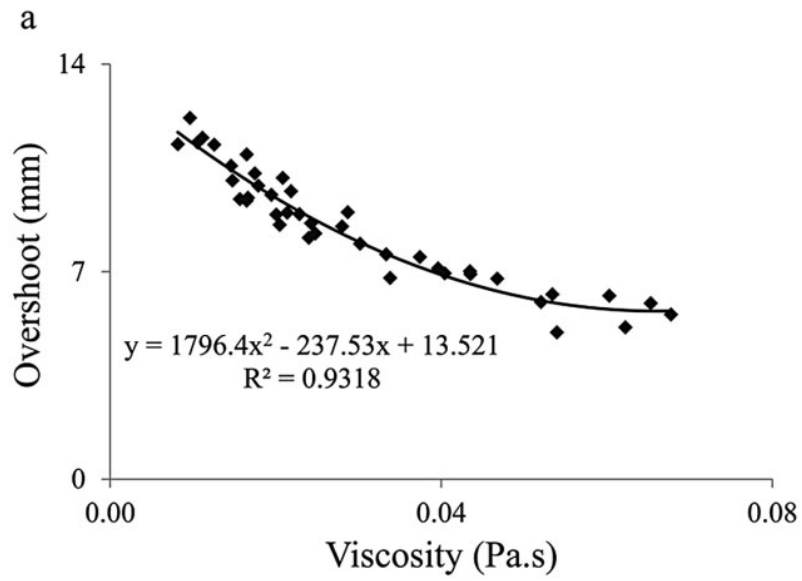

$\mathrm{b}$

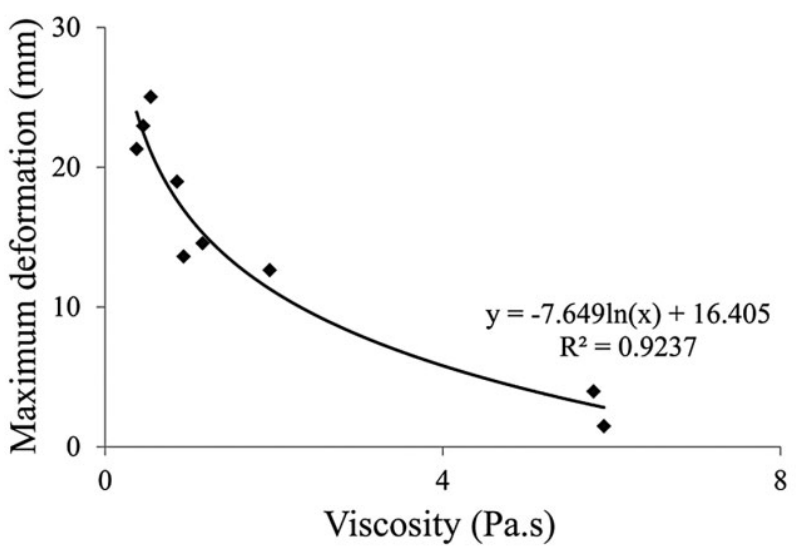

FIG. 13. CORRELATION BETWEEN THE OVERSHOOT AND THE VISCOSITY FOR 12 OIL AND FAT TYPES AT DIFFERENT TEMPERATURES (A) AND CORRELATION BETWEEN THE MAXIMUM DEFORMATION AND THE VISCOSITY FOR NINE MOLTEN CHOCOLATE SAMPLES (B) 
the rheometer data (the viscosity) at all measurement temperatures for the oil and fat samples (Fig. 13a) as well as the molten chocolate samples (Fig. 13b) is presented. Measurements on oils and fats, and molten chocolate gave good curvilinear correlations $\left(R^{2}>0.9\right)$. Hence, the FPD is also capable for measuring oils and fats, as well as molten chocolate.

\section{CONCLUSIONS}

The FPD is a new rheological measurement device, which applies a controlled air pulse to the product surface and measures the subsequent deformation of the surface. The applicability of this device was studied for use on viscous food products such as sugar and fat-based systems.

The correlation coefficients between the FPD and the rheometer data were strong. Sugar solutions showed a strong linear relationship between the maximum deformation and the viscosity. For fruit purees and concentrates, oils and fats, and molten chocolate, strong curvilinear correlations were established between the maximum deformation (or overshoot) and the viscosity. Furthermore, small standard deviations were obtained and the temperature dependency could be demonstrated with the FPD. These results pointed out the applicability of the FPD for a wide range of food products, i.e., products with a wide viscosity range. Moreover, the FPD is well suited for in-line applications because it is an easy, fast, noncontact and nondestructive measurement. Besides in-line applications, the FPD is also appropriate for R\&D applications because it is an accurate device with strong correlations with classical rheological methods. When more detailed information about the rheological characteristics is needed, the integrated PLS in the software of the FPD can be used. In further work, viscoelastic food products will also be studied.

\section{REFERENCES}

AFOAKWA, E.O., PATERSON, A., FOWLER, M. and VIEIRA, J. 2009. Comparison of rheological models for determining dark chocolate viscosity. Int. J. Food Sci. and Tech. 44, 162-167.

BAMELIS, F.R. and DE BAERDEMAEKER, J.G. 2006. Use of the Foodtexture Puff Device to monitor milk coagulation. J. Dairy Sci. 89, 29-36.

BOURNE, M.C. 2002. Food Texture and Viscosity: Concept and Measurement, Academic Press, New York, NY.

HUNG, Y.-C., PRUSSIA, S.E. and EZEIKE, G.O.I. 1999. Non destructive firmness sensing using a laser air-puff detector. Postharvest Biol. Technol. 16, 15-25.

KIM, J., KIM, D.N., LEE, S.H., YOO, S. and LEE, S. 2010. Correlation of fatty acid composition of vegetable oils with rheological behaviour and oil uptake. Food Chem. 118, 398-402.

LEE, Y.S., OWENS, C.M. and MEULLENET, J.F. 2008. A novel laser air puff and shape profile method for predicting tenderness of broiler breast meat. Poult. Sci. 87, 1451-1457.

MCGLONE, V.A. and JORDAN, R.B. 2000. Kiwifruit and apricot firmness measurement by the non-contact laser air-puff method. Postharvest Biol. Technol. 19, 47-54.

MCGLONE, V.A., KO, S.M.W. and JORDAN, R.B. 1999. Non-contact fruit firmness measurement by the laser air-puff method. Trans. Am. Soc. Agric. Eng. 42, 1391-1397.

PRUSSIA, S.E., ASTLEFORD, J.J., HEWLETT, B. and HUNG, Y.-C. 1994. Non-destructive firmness measurement device. Patent No.. 5.372.030. United States.

QUINTAS, M., BRANDÃO, T.R.S., SILVA, C.L.M. and CUNHA, R.L. 2006. Rheology of supersaturated sucrose solutions. J. Food Eng. 77, 844-852.

RECONDO, M.P., ELIZALDE, B.E. and BUERA, M.P. 2006. Modeling temperature dependence of honey viscosity and of supersaturated model carbohydrate systems. J. Food Eng. 77, $126-134$.

SOESANTO, T. and WILLIAMS, M.C. 1981. Volumetric interpretation of viscosity for concentrated and dilute sugar solutions. J. Phys. Chem. 85, 3338-3341.

YOĞURTÇU, H. and KAMIŞH, F. 2006. Determination of rheological properties of some pekmez samples in Turkey. J. Food Eng. 77, 1064-1068. 